\title{
Producción de penicilina en Chile entre 1944 y 1954
}

\author{
Cecilia Ibarra y Mirtha Parada
}

Sociedad Consultora Sistemas Sustentables y Universidad de Chile (CI).

Instituto de Salud Pública (MP).

Recibido: 17 de noviembre de 2014

Correspondencia a: Cecilia Ibarra M Cecilia.ibarrachile@gmail.com, Cecilia.ibarra@vtr.net

\section{Penicillin production in Chile between 1944 and 1954}

Penicillin production in Chile was a pioneering development; however there is not much information to learn about it. The Chilean Institute for Bacteriology (Instituto Bacteriológico de Chile) produced penicillin between 1944 and 1973. The stage starting in 1953 is better known since there was an agreement with United Nations. Our research focused on building a story about production between 1944 and 1954 based on archival information and the national and international historic context. Our results place Chile amongst the pioneer countries in the successful industrialization of the drug. Our conclusions are that this was a proper industrial production as opposite to a pilot plant - a name commonly used to call the early factory. We explain the production plant trajectory by making relations between technological change and governance. Finally, we believe the later expansion of the plant, in the context of the agreement with the United Nations, took place under unpromising governance conditions, which called for passive innovation and technology management.

Key words: Penicillin, production, Chilean technological history, Instituto Bacteriológico de Chile.

Palabras clave: Penicilina, producción, historia de la tecnología en Chile, Instituto Bacteriológico.

\section{Introducción}

$(1$ hile produjo penicilina de manera ininterrumpida entre 1944 y 1973 bajo la dependencia del actual Instituto de Salud Pública (ISP). Los antecedentes más conocidos corresponden al período que parte en $1954^{1-4}$. Sin embargo, entre principios de 1944 y 1954 hay

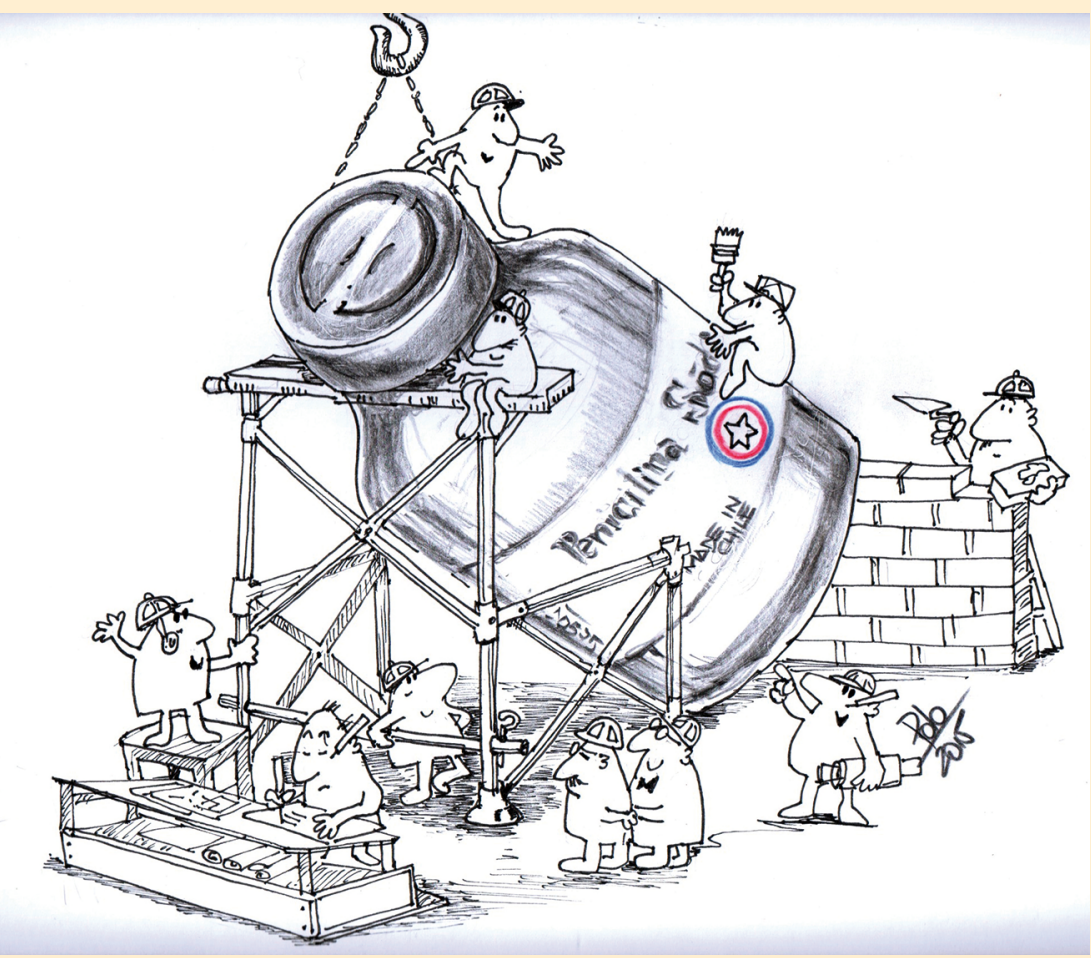

una historia sorprendente de innovación tecnológica de carácter pionero a nivel mundial. Esta historia aparece al escudriñar en las actas del Consejo Directivo del Instituto Bacteriológico de Chile (IB), institución que precedió al actual ISP.

El objetivo de nuestra investigación fue construir un relato sobre la producción de penicilina chilena entre 1944 y 1954 a partir de archivos de la época y del contexto histórico nacional e internacional. Este trabajo viene a complementar la Nota Histórica del Dr. Walter Ledermann ${ }^{3}$ que es -hasta donde sabemos- la única referencia bibliográfica sobre la fabricación de penicilina chilena y el cierre de la planta en 1973.

\section{Metodología}

Nuestra investigación comenzó en el ISP, nos parecía que la planta de penicilina debía tener reconocimiento como patrimonio tecnológico del Instituto. Sabíamos que hubo producción de penicilina al menos desde 1954, con la llamada planta UNICEF, y que había alguna investigación e incluso producción previa de carácter piloto o de pequeña escala ${ }^{1-4}$.

En el marco de nuestro trabajo inicial entrevistamos a personas que trabajaron en la planta durante los últimos años de producción y que vivieron el proceso de cierre. Las primeras luces de la importancia que podía tener el período anterior a 1954 provinieron de estas entrevistas.

Recurrimos a archivos históricos para construir un relato sobre lo que había sido este primer período. Los libros de actas del Consejo del IB constituyeron nuestra principal fuente de referencia. Usamos como fuentes 
adicionales: decretos, resoluciones, oficios, boletines y revistas de la época.

Decidimos situar el proceso de producción en un contexto internacional y de condiciones nacionales, centrándonos en aspectos de desarrollo tecnológico y de gobernanza. Comprendemos la tecnología en su sentido amplio, incluyendo tanto los sistemas físicos como las características sociales y culturales. Entendemos por gobernanza la organización de la acción colectiva que incluye aspectos de estructura -cómo se toman las decisiones-, control -el poder de tomar decisiones en esas estructuras-, y proceso-la implementación de la estructura y el control ${ }^{5}$.

Usamos referencias de la literatura científica sobre la historia de la medicina y la farmacología e hicimos un paralelo entre el desarrollo internacional de la industria y los avances del caso chileno. Esto nos permitió situar la actividad chilena en la arena internacional.

\section{Los inicios de la producción industrial de penicilina y su uso clínico: 1940-1944}

El uso clínico de penicilina se desarrolla durante la segunda guerra mundial en los países aliados. Chile en la década de 1940, aún tenía un alto índice de mortalidad por causa de enfermedades prevalentes, como tuberculosis, y enfermedades con un alto porcentaje de mortalidad en los hospitales, por ejemplo la fiebre tifoidea y la disentería. Entre las patologías de la época destacaba la sífilis, tanto por las dificultades que existían en su tratamiento como por las consecuencias y connotaciones sociales que implicaba. Tuberculosis, sífilis y fiebre tifoidea era llamadas "enfermedades sociales", que no eran sino la expresión clínica de la miseria, el hacinamiento, la carencia de una vivienda higiénica y de las extremas condiciones laborales a las que estaban sometidos miles de chilenos. Con la introducción de las sulfas y la penicilina en los años cuarenta disminuyeron notablemente las cifras de mortalidad en el país, aunque no como se esperaba, debido a la urbanización deficiente que influyó negativamente en las tasas de mortalidad ${ }^{6}$.

\section{Producción mundial y liderazgo}

La producción industrial de penicilina en el mundo tiene sus comienzos en el período que va entre 1940 y 1944. A partir del descubrimiento del penicillium y posterior desarrollo del método para su aislamiento y cultivo en Inglaterra, se inician procesos de aprendizaje y desarrollo tecnológico en distintas partes del mundo. Los principales países involucrados en la industrialización de la penicilina fueron Canadá, los Estados Unidos de América (E.U.A.) e Inglaterra, quienes tuvieron relaciones de colaboración para perfeccionar los métodos de producción ${ }^{7}$. Las naciones europeas que contaban con capacidades científicas y podrían haber iniciado su propia industria, se vieron restringidas por las condiciones impuestas por la guerra ${ }^{8,9}$.

Estados Unidos de América tomó la delantera en la industrialización de la penicilina, tanto en métodos para la fabricación masiva como en cantidades producidas. Los esfuerzos de investigación y desarrollo fueron coordinados por el estado, que formó un comité de producción de guerra, the War Production Board ${ }^{10}$. Empresas norteamericanas como Pfizer Inc., Merck \& Co. y E. R. Squibb and Sons, las dos primeras fundadas en E.U.A. por científicos inmigrantes alemanes y la tercera por científicos norteamericanos, aumentaron su producción al alero y asesoría de este comité. El Ministerio de Agricultura estadounidense apoyó la producción de un insumo derivado del maíz en la etapa de gestación de la industria ${ }^{11,12}$.

\section{La penicilina vista desde la comunidad de salud en Chile}

En Chile se sabía del descubrimiento de la penicilina y se tenían antecedentes de sus propiedades y promesas para el alivio de enfermedades infecciosas, pero no era posible predecir cuándo y en qué condiciones se tendría acceso a este medicamento. En esa época las enfermedades infecciosas tenían una alta incidencia en la población chilena. Según las recopilaciones del Dr. Kraljevic ${ }^{13}$, éstas constituían la causa principal de morbilidad y mortalidad en el país en las décadas de 1920 y 1930 . Disponer de penicilina ayudaría a combatir enfermedades que atacaban a la población chilena y que hasta ese momento no tenían cura.

Podemos asegurar que la comunidad médica tenía información actualizada de los avances del uso clínico de penicilina porque éstos eran reportados por Revista Médica de Chile, el medio científico más antiguo del área, y por otras revistas de salud. La búsqueda exhaustiva en los volúmenes de Revista Médica arrojaron la primera referencia a penicilina en el volumen del año 1942 -única referencia en ese volumen- en la sección "Revista de Revistas" donde se resume un artículo sobre actividad antibacteriana publicado en Proceedings of the Staff Meetings of the Mayo Clinic, sobre la investigación de la época comparando la efectividad de la penicilina in vitro. Al año siguiente aparecen cuatro referencias en la misma sección, correspondientes a resúmenes de artículos de revistas internacionales que dan cuenta de resultados positivos del uso clínico de penicilina en el extranjero. En el volumen de 1944 todos los números hacen alguna mención a la penicilina. Aparece un total de 15 resúmenes de artículos internacionales sobre resultados exitosos de tratamientos, con cada vez mayor número de pacientes. Además, se publican los primeros artículos nacionales: uno que informa sobre desarrollo de penicilina a la fecha ${ }^{14}$, otro sobre uso clínico ${ }^{15} \mathrm{y}$ los primeros cuatro casos clínicos nacionales presentados a la Sociedad Médica de Santiago $^{16-19}$. La mayoría de los artículos hacen referencia a la dificultad de conseguir penicilina, los dos primeros casos clínicos -presentados en octubre de 1944- agradecen la entrega de penicilina por parte de la embajada de E.U.A. Los segundos, presentados en noviembre del mismo año -al igual que todas las publicaciones de ahí en adelante-no indican la procedencia de la penicilina. Es probable que se 
deje de mencionar debido a que en esa época la penicilina de la que disponía el país comenzó a asignarse de manera centralizada en consideración a los casos justificados que la requerían. La asignación estuvo a cargo de la Comisión de la Penicilina (CIB, Acta $N^{\circ}$ 97, 1944: 232) presidida por el Dr. Horwitz e integrada -entre otros- por el Dr. Kraljevic $^{20,21}$. La salud de la población era una prioridad de la política pública. El Ministro de Salubridad, Salvador Allende, señalaba en su libro La realidad médico- social el lema "gobernar es educar y dar salud al pueblo"22.

\section{El IB y la producción nacional de penicilina}

El IB, creado en 1929 como predecesor del Instituto de Higiene (Ley 4.457, 1929), tenía como objetivos formar bacteriólogos para el país, producir insumos biológicos y bioquímicos para su uso en salud, y controlar la producción y venta de estos productos en el país. La dirección del IB estaba a cargo de un Consejo Superior, en 1936 una modificación determinó que el IB pasara a depender del Ministerio de Salubridad Pública y que el Consejo fuese presidido por el Ministro y contara como consejeros al Director General de Sanidad, el Director General de Asistencia Social, el Decano de la Facultad de Medicina de la Universidad de Chile, dos miembros elegidos por el Presidente de la República y el Director y el Gerente General del IB.

En 1952, la Ley 10.303, que creó el Servicio Nacional de Salud (SNS), decreta la dependencia del IB bajo el SNS y la desaparición del Consejo Superior del IB. A partir de esta nueva ley, la administración del IB queda en manos de un director, un gerente de finanzas y un consejo técnico asesor formado por los jefes de los departamentos técnicos.

Las actas del Directorio del IB -se usa Directorio hasta noviembre de 1943 y Consejo de ahí en adelante- se refieren a las actividades de producción a las que se agregaría la fabricación de penicilina nacional. A fines de 1943, el Directorio recibió el "Informe de producción del Instituto" frente al cual se registran reacciones de orgullo por lo que representaba para el país la producción nacional. Hay una aprobación general a la política seguida de distribución de productos casi exclusivamente de elaboración propia y haberse "negado siempre a servir de distribuidor $y$ envasador" y de constituir una fortaleza en capacidades de producción lo que "ha sido de enorme importancia en la crisis (1932-33) y en los años corridos de la actual guerra, acompañado de las conocidas dificultades de importación... Basta recordar en este momento que el Instituto ha sido acaso el único proveedor del país de sueros, de arsenicales...." (Directorio IB, Acta $\mathrm{N}^{\circ} 6$, noviembre, 1943).

El IB tenía dentro de sus funciones, la investigación para la formación de profesionales y para el desarrollo de nuevos productos; es en este contexto que los profesionales técnicos del IB, Dr. Armijo y Q. F. Saitúa, comenzaron a experimentar con la producción de penicilina a nivel de laboratorio. La primera mención a la fabricación de penicilina en las actas del Consejo IB (CIB) fue en marzo de 1944:

El Dr. Prado [Director(s)] informa extensamente sobre los trabajos efectuados para preparar en el Instituto la penicilina. Estos trabajos comenzaron en cuanto llegaron noticias del extranjero y durante el primer tiempo se efectuaron diversas investigaciones hasta obtener técnicas modificadas que han permitido producir una buena cantidad de esta droga ... y deja especial constancia de ello que la fabricación del producto se hace con el 100\% de materia prima nacional tanto en la parte física como en la parte técnica ya que, repite se ocupan técnicas estudiadas en el país".

CIB, Acta $\mathrm{N}^{\circ} 97,1944:$ 231-232

Como conclusión de dicha sesión, el Consejo acuerda felicitar a los técnicos que han participado en tan importante desarrollo, preparar un comunicado oficial para la prensa y enviar agradecimientos a los laboratorios de Toronto por la cooperación prestada, que fue gestionada por la Embajada de Chile en Canadá. Además, el Consejo decide formar una Comisión para el control clínico y Bacteriológico de la penicilina usada en Chile. Finalmente, otorgan licencia para que el Dr. Armijo acepte la invitación de gobierno de E.U.A. para visitar los laboratorios donde se produce penicilina y agradece al Ministro de Salud porque el Ministerio se hará cargo de los costos del viaje (CIB, Acta N97, 1944).

El "Bacteriológico" estaba lanzado en la aventura y la responsabilidad de asegurar la provisión de penicilina para el país, en un momento en el que no se tenía un pronóstico de la disponibilidad y condiciones de venta de la droga en el mercado internacional. Unos meses más tarde había completado un proceso de vigilancia tecnológica internacional del que se da cuenta en la reunión de agosto de 1944 (CIB, Acta Nº100, 1944: 244-247). El Dr. Suárez viajó a E.U.A. en abril y allá se encontró con el Dr. Armijo, que hacía su visita técnica, se le unió la Srta. Leyton, que estaba en una capacitación en ese país, para aprender los procesos químicos de la producción de penicilina. El Dr. Suárez informó al Consejo que debió recurrir a sus contactos personales para realizar visitas y reunir información, puesto que ésta era reservada. La producción industrial estadounidense se había iniciado hacía un año y medio y ya se había duplicado el volumen de producción y reducido los costos a un quinto. El método preferido, por su eficiencia, era la fermentación profunda y los productores más importantes eran Pfizer Inc., Merck \& Co. y E. R. Squibb and Sons (que formaban un consorcio), otro gran productor que visitó era Comercial Solvents. La producción estadounidense contaba con asistencia técnica y regulación centralizada:

El gobierno a través del War Production War tiene completo control de lo hecho en estos laboratorios y va a proporcionar a cada fábrica los elementos 
necesarios y la ayuda técnica que van pidiendo, pero las fábricas desarrollan sus plantas industriales por su propia iniciativa, por sus ingenieros y por su cuerpo de investigadores así mejoran y llegan a su gran producción industrial y reducción de costos.

$$
\text { (CIB, Acta N¹00, 1944:246). }
$$

El Dr. Suárez informa de las visitas a laboratorios y plantas y de sus gestiones para adelantar posibles convenios de royalty. La compañía Sherley se le acercó para ofrecerle un acuerdo, pero él la desestimó porque usaba procedimientos fuera de las técnicas oficiales de E.U.A. Su conclusión es que en Chile "se conoce en detalle la técnica de producción de penicilina, la planificación de estanques experimentales y se tiene toda la información oficial que sirve de base a las fábricas para montar instalaciones" (CIB, Acta N¹00, 1944:246). No obstante, es de la opinión de buscar alianzas:

Creo poco prudente y muy dificil de realizar el que nosotros sin ayuda técnica de alguna de estas grandes plantas lleguemos a montar una producción con la capacidad suficiente para abastecer el país y que pudiese producir penicilina a un precio de competencia con la sobreproducción que habia en Estados Unidos.

$$
\text { (CIB, Acta N¹00, 1944:246). }
$$

Su postura levanta la disyuntiva respecto de producir con recursos propios o asociarse con laboratorios internacionales. El Ministro "hace presente que el Consejo deberá resolver si el instituto debe o no fabricar penicilina" (CIB, Acta N 100, 1944: 247). El Consejo decide explorar ambas posibilidades a fin de tomar una decisión informada. A pesar de sus dudas, el Ministro provee fondos para montar un estudio experimental de elaboración de penicilina, que permitiría evaluar la alternativa de producción nacional autónoma (CIB, Acta $\mathrm{N}^{\circ} 100,1944$ : 247). En la misma sesión se decide enviar un cable a los productores líderes en el mundo manifestando interés por asociarse para producir penicilina en Chile.

Mientras los estudios experimentales avanzan y producen resultado, las negociaciones para asociarse a un laboratorio internacional reconocido no prosperan. El Consejo recibe rotundas negativas por parte de Merck \& Co. (CIB, Acta $\left.\mathrm{N}^{\circ} 101,1944: 249\right)$ y de la casa E. R. Squibb and Sons (CIB, Acta $\mathrm{N}^{\circ}$ 102, 1944: 260-261). Después de conocidas estas noticias, envían al Dr. Hoffmann a E.U.A. en viaje de estudios relacionado con la penicilina (CIB, Acta $\mathrm{N}^{\circ} 102,1944$ : 260-264).

\section{Decisión de iniciar la producción de penicilina en Chile: 1945}

Al término de la segunda guerra mundial muchos países tenían serios problemas de salud, la sífilis, por ejemplo, pudo haberse convertido en una epidemia de no haber sido por el tratamiento con penicilina ${ }^{23}$. En 1945 la droga era escasa y sólo E.U.A. había logrado una producción suficiente como para satisfacer su consumo local ${ }^{24}$.

El 23 de abril de 1945, ocho meses después de destinar financiamiento a la experimentación:

El Consejo toma conocimiento del Informe presentado por los Drs Hoffman, Armijo y Sr. Saitúa con respecto de la futura producción de penicilina en el Instituto......El Consejo toma conocimiento de estas informaciones y acuerda autorizar la instalación inmediata de dicha plata para lo cual dispone de $\$ 1.000 .000$ que serán proporcionados por el Supremo Gobierno con el Decreto $N^{\circ} 738$ del Ministerio de Vias y Obras.

$$
\text { CIB, Acta Nº106, 1945:12 }
$$

No obstante, en la sesión del mes siguiente se vuelve a discutir el tema. El Consejo decide revisar su decisión y pedir una proyección del negocio para evaluar la factibilidad, debido a dudas surgidas por los bajos costos de producción que tiene E.U. A. El Acta reporta una aireada discusión respecto de instalar o no la planta. Finalmente se decide por unanimidad dar curso a la planta de producción (CIB, Acta $\mathrm{N}^{\circ}$ 107: 15-17)

La planta se convierte en realidad, en 1945 se construye y marcha en piloto y en 1946 está produciendo comercialmente. La sesión de julio de 1945 da cuenta de las inversiones realizadas (CIB, Acta $\mathrm{N}^{\circ} 108,1945$ : 28) y la de diciembre de los resultados piloto y de las ventas proyectadas para 1946 (CIB, Acta $\left.N^{\circ} 110,1945\right)$. En julio de 1946 se reporta al Consejo del funcionamiento de la planta y de la visita del científico pionero en el descubrimiento e industrialización de la penicilina, Dr. Florey (CIB, Acta $\left.N^{\circ} 113,1946: 70\right)$, quien dice que sólo ha visto plantas en E.U.A., Canadá e Inglaterra -al parecer no conocía la planta brasilera que funcionaba en el Instituto Oswaldo $\mathrm{Cruz}^{25}$.

\section{Innovación tecnológica y expansión de la producción: 1946 a 1951}

Terminada la guerra, se establecieron procesos productivos más eficaces, los volúmenes de penicilina aumentaron y la producción se expandió a distintos países. En esta etapa la innovación tecnológica se concentró en adquisición y adaptación en nuevas localidades y mejora de procesos.

\section{La carrera internacional por aumentar producción $y$ eficiencia}

Los beneficios de la penicilina eran ampliamente reconocidos y valorados a nivel mundial, y las naciones hacían esfuerzos por tener acceso a la droga. En 1946 Inglaterra logró cubrir su propia demanda y, el mismo año, la producción ya estaba expandiéndose en Europa y Asia. 
Los gobiernos instalaron sus propias plantas productivas o fomentaron el desarrollo bajo argumentos de asegurar el abastecimiento para sus naciones y mantener control sobre un recurso tan estratégico ${ }^{26}$.

El crecimiento explosivo de la producción post-guerra se explica, en parte, porque existía un nivel de aprendizaje tecnológico de los científicos de varios países bajo dominación nazi. Los científicos habían experimentado en preparaciones de la droga a partir de las primeras publicaciones del equipo de Oxford y su conocimiento fue clave para el desarrollo de la industria global ${ }^{27}$. En el caso de Japón, la larga tradición del país en procesos fermentativos permitió acortar las brechas productivas y convertirse en líderes en el desarrollo de antibióticos al cabo de 15 años $^{28}$.

Canadá tiene un rol importante en la difusión de las técnicas de producción debido a que presta asistencia técnica a las nuevas plantas. En 1946 y 1947 asesoró los incipientes desarrollos en Italia y las Repúblicas soviéticas La planta austriaca se consolida en 1948 con una gran producción. La planta italiana, que cuenta con financiamiento de Naciones Unidas y es dirigida por Chain, se perfila como un centro de investigación y desarrollo para la producción de antibióticos. Ya en 1950 la producción había aumentado considerablemente en Austria, Italia y también en Japón ${ }^{29}$.

\section{Chile en la carrera tecnológica y la expansión de la producción}

Si bien la instalación de la planta chilena provocó aireadas discusiones respecto de la proyección del negocio considerando la disminución de precios en Estados Unidos (CIB, Acta $\mathrm{N}^{\circ}$ 107, 1945: 14-16), la planta productiva comenzó a funcionar en 1946 (CIB, Acta No 113, 1946: 70), después de dos años de actividades experimentales y piloto. La producción se desarrolló en un ambiente de creciente presión por aumentar las cantidades producidas, mejorar la eficiencia y mantenerse al ritmo del cambio tecnológico que se observaba en la industria internacional.

Se gestionaron desafíos tecnológicos tales como la incorporación de la técnica de cristalización. Es así como en 1947 se cristalizó la penicilina producida en Chile, para lo cual se entró en negociaciones con Connaught Medical Research Laboratories (CIB, Acta $\mathrm{N}^{\circ} 119,1947$ ).

La planta abastecía el $25 \%$ de la demanda nacional. En marzo de 1948 se entrega al Consejo un completo informe sobre la producción de penicilina que motiva una conversación sobre hacer una gran planta que pueda satisfacer el consumo local e incluso exportar A fin de explorar esta idea se decide enviar al Dr. Armijo y el Sr. Saitúa a conocer las instalaciones productivas brasileras (CIB, Acta $\mathrm{N}^{\circ} 121,1948$ ).

Las conversaciones sobre una ampliación de la producción no avanzan debido a los problemas presupuestarios que son materia recurrente en la gestión del Instituto. Un año después, en marzo de 1949, se discute la compra de un equipo bajo el argumento del ahorro de divisas que significará la ampliación de la producción, pero la discusión sobre una nueva planta no se retoma (CIB, Acta $\mathrm{N}^{\circ}$ 125, 1949). En septiembre del mismo año, se reporta al Consejo que la producción nacional sólo cubre $20 \%$ del consumo, las conversaciones vuelven sobre las posibles asociaciones y royalties con laboratorios internacionales. Se han tenido conversaciones con Squibb en Buenos Aires y se han recibido cartas de laboratorios estadounidenses y canadienses. Deciden mandar al Dr. Hoffmann a obtener información en terreno sobre estas posibles alianzas (CIB, Acta $\mathrm{N}^{\circ} 129,1949$ ).

A fines de año, en la sesión de Diciembre de 1949, el Consejo concluye que están las condiciones para ampliarse y construir una gran planta, pero es necesario solucionar el problema de financiamiento."El negocio es de vital importancia para la salud pública y para la economía del país "(CIB, Acta $\left.\mathrm{N}^{\circ} 132,1949: 218\right)$.

Se estudian posibles convenios y acuerdos tanto para ampliar la producción como para importar a granel y envasar en Chile. Las actas hacen mención a conversaciones en esta línea con los laboratorios Petrizzio y Cohas Pfizer (CIB, Acta $\left.\mathrm{N}^{\circ} 135,1950\right)$. El primero se descarta y, en la discusión sobre el segundo, el Ministro hace presente que no le parece adecuado comprometer exclusividad con una empresa, clausula exigida en los convenios. El Ministro es de la opinión de mantener independencia frente a los laboratorios y que, por lo tanto, la ampliación debe hacerse con fondos propios:

Como era absurdo terminar con el Instituto en razón de lo que significa un capital representado por lo técnico y el valor cientifico de sus veinte años de trabajo, el gobierno ha resuelto ayudarle y para ello está dispuesto a proporcionarle los medios económicos con el fin de que pueda ampliar su planta de penicilina, a la que servirá para financiar su situación económica y desarrollar sus funciones en forma tranquila y eficiente. Naturalmente que para ello es indispensable que el gobierno vea que el Instituto está con sus manos libres y no se encuentra amarrado a contrato alguno. En consecuencia reitera que el gobierno proporcionará los fondos necesarios para la Planta de Penicilina, por cuanto el Instituto ha demostrado que gracias al trabajo, al esfuerzo y la técnica de sus médicos chilenos que han ... (ilegible) en este problema, se pudo resolver, sin ayuda extranjera. Agrega que, en caso que más adelante se necesitaran técnicas extranjeras, estas podrán adquirirse mediante pago de un "royalty".

CIB, Acta $\mathrm{N}^{\circ} 135,17$ de marzo de 1950: 233-234

Ante tal compromiso, el Director del Instituto, Dr. Suárez, agradece las palabras del Ministro y el debate concluye con las decisiones de no aceptar contratos con laboratorios externos y ampliar la planta de penicilina con 
fondos provistos por el gobierno. El "Bacteriológico" se aboca a la tarea de ampliar su producción. Un año después se rinde cuentas al Consejo de las compras de equipos con las que se espera duplicar la producción -que alcanzaba en ese momento a $25 \%$ del consumo nacional. La compra correspondía a compresoras que estaban disponibles en el país debido a que eran usadas por la minería (CIB, Acta $\mathrm{N}^{\circ} 136$, junio de 1950).

Entre la decisión de ampliación y la rendición sobre compras de equipos, las condiciones del mercado cambiaron. Los laboratorios bajaron sus precios y hubo un cambio en la divisa que abarataba las importaciones (CIB, Acta 136, 7 de junio de 1950).

El primer registro de convenio de cooperación internacional para la ampliación de la planta de penicilina data de julio de 1951 (CIB, Acta No 146, 6 de julio de 1951). Se informa de la visita del Director médico de UNICEF quien anunció que se otorgará la ayuda al Instituto. El convenio se iniciaría con una visita técnica de expertos canadienses para evaluar las necesidades de ampliación y con la preparación de tres especialistas del Instituto que irían a hacer becas de perfeccionamiento en: bacteriología -Dr. Armijo-, química-Sr. Saitúa-, e ingeniero - por contratar.

El año 1951 fue complejo para la planta debido a que estaba en remodelación, recibiendo nuevos equipos y con la perspectiva del convenio internacional. Además, la situación se vio agravada porque los proveedores de penicilina a granel -que era envasada por el laboratorio para completar la demanda del Servicio de Salud- no despacharon los pedidos a tiempo y el Instituto se vio en situación de incumplimiento con el Servicio de Salud (CIB, Acta $\mathrm{N}^{\circ} 149,9$ de noviembre de 1951).

\section{Gestación de la planta UNRA: 1952-1954}

La nueva planta de producción de penicilina fue una realidad en 1955. La producción se inició en 1956 y en 1957 se logró superar el consumo nacional anual, produciendo un superávit. Esta sección corresponde a la etapa previa a la inauguración de la nueva planta de penicilina en el marco de un convenio de cooperación entre el gobierno de Chile y las Naciones Unidas y en un contexto donde la producción internacional estaba dominada por grandes laboratorios.

\section{Los grandes actores internacionales}

Con el fin de la guerra la producción de penicilina se había expandido por el mundo. Los países aspiraban a tener independencia para proveerse del antibiótico. Las Naciones Unidas - a través de sus comisiones UNRRA y WHO, prometía brindar apoyo a diversas naciones para instalar sus propias plantas como parte del esfuerzo de reconstrucción post-guerra y de la separación entre oriente y occidente. Este apoyo se concretó recién en 1948 con la planta italiana, que fue dirigida por Chain y se convirtió en un instituto líder en el desarrollo de la microbiología que daría asistencia técnica a las nuevas plantas de penicilina auspiciada por las Naciones Unidas- las plantas UNRRA instaladas posteriormente en Yugoslavia, India y Chile. La producción de penicilina marcó un hito en 1951 cuando la planta austriaca Biochemie, que producía exitosamente desde 1948, comercializó la Penicilina V, que tenía la propiedad de no destruir el ácido del estómago, lo que significó sumar a la penicilina inyectable, un producto que podía tomarse en tabletas. En la década de 1950 la producción de penicilina creció y se concentró en grandes laboratorios internacionales ${ }^{30}$.

\section{El Convenio UNNRA- Gobierno de Chile}

Las aspiraciones de ampliar la producción de penicilina en el Instituto habían encontrado acogida en las Naciones Unidas (CIB, Acta $\mathrm{N}^{\circ}$ 146, julio de 1951: 329). UNICEF asistiría al gobierno de Chile para establecer una planta de penicilina con capacidad para producir 1.800 .000 mega unidades anuales*. El aporte de UNICEF consistió en US\$ 285.000 para importar equipo, indicado por un asesor nominado por WHO y US\$ 50.00 para asistencia técnica consistente en becas para capacitar técnicos chilenos y para solventar los costos de consultores de WHO que darían asistencia técnica en distintas etapas del proceso de establecimiento de la planta. El gobierno de Chile aportaría todos los costos de construcción de la planta, valorizados en US\$247.000. Los costos de operación se estimaron en US\$ 350.000 anuales que serían solventados con la venta del producto al Servicio de Salud ${ }^{31}$.

La recomendación de las Naciones Unidas para hacer sus aportes se basó en la importancia de la provisión de penicilina para Chile, donde la tasa de mortalidad infantil era alta, lo mismo que de las enfermedades infecciosas. Se argumentó que al menos la mitad de la penicilina era distribuida gratuitamente para madres e hijos en el sistema de beneficencia pública y que la importación del antibiótico representaba un drenaje de divisas para el sistema de salud. UNICEF consideró que había una demanda suficiente como para justificar la producción en Chile, que el IB contaba con experiencia, personal capacitado para emprender producción a mayor escala -contando con alguna ayuda técnica-, y que el gobierno le daba alta prioridad a este proyecto. El reporte estimó que la producción nacional en 1950 correspondía a 10\% de la demanda. Una planta en Chile podría ser parte del grupo internacional de investigación que estaba formando WHO, que daba capacitación e intercambiaba información para la producción ${ }^{32}$.

\section{Transición hacia una mayor escala productiva}

La firma del convenio entre el gobierno de Chile y las Naciones Unidas desencadenó una línea de acción dentro del IB para preparase para la expansión de la producción.

\footnotetext{
* La estimación de demanda que se hace en el reporte es de 2.000 mega unidades anuales.
} 
El Dr. Armijo partió a Italia a capacitarse en el instituto del célebre Dr. Chain. El IB creó un cargo de ingeniero previendo la expansión de la planta (CIB, Acta $\mathrm{N}^{\circ} 155$, mayo de 1952) y se dio trabajos para asegurar el suministro de lactosa que necesitará la nueva planta.

El IB necesitaba contratar la entrega anual de 250 toneladas de lactosa a partir de 1954 (fecha estimada de inicio de actividades de la nueva planta). La información que habían obtenido del Instituto de Economía Agrícola era que no existían proveedores nacionales y que la fabricación era dificultosa y la inversión alta. El precio internacional de la lactosa era elevado y depender de un insumo importado resultaba un riesgo y un gasto de divisas. El IB finalmente solucionó el problema aceptando la oferta del único proveedor que tomó el desafío y elaborando un cuidadoso contrato que resguardaba las eventualidades de atraso en el comienzo de la producción y variaciones en los volúmenes requeridos (CIB, Acta $\mathrm{N}^{\circ}$ 157, 26 de julio de 1952). El desarrollo de proveedor para este insumo resultó exitoso puesto que no hay nuevas menciones al asunto durante el funcionamiento de la planta, el suministro resulta transparente.

La entrega de los aportes por parte del gobierno para iniciar la construcción del edificio se dilata (CIB, Acta $\mathrm{N}^{\circ} 160$, octubre de 1952), pero finalmente, la ley de presupuesto compromete $\$ 4.100 .000$ para la instalación de la planta de penicilina (Ley 11.137, 27 de diciembre de 1952). Ese año, aún antes de la nueva planta, la penicilina era una fuente de ingreso importante para el IB (CIB, Acta $\mathrm{N}^{\circ} 161$, noviembre de 1952).

Firmado el convenio con las Naciones Unidas y con presupuesto aprobado, en enero de 1953 había suficientes avances para decidir la adjudicación de la construcción del nuevo edificio (CIB, Acta $\mathrm{N}^{\circ} 163$, enero de 1953). El IB había completado con éxito la preparación de planos de arquitectura del edificio. Estos fueron realizados por una empresa chilena que había trabajado el pabellón de virus y con la que ya tenían buena experiencia y un buen modelo de contrato. Los planos terminados fueron enviados a los asesores de Naciones Unidas en Canadá y habían sido aprobados. Habían solucionado la provisión de lactosa y, aunque a mayor precio que la que se envasaba en E.U.A., era materia prima nacional. Buscaban una solución para la provisión de envases puesto que había un monopolio internacional que encarecía los precios, estimaron establecer una planta y el Ministro de Salud ofreció hacer una llamado a todos los productores de vidrio del país para plantearles el problema y pedir propuestas, que de no ser satisfactorias obligarían al Servicio de Salud a traer plantas automáticas (CIB, Acta $\mathrm{N}^{\circ} 163$, enero de 1953). Así avanzaban las cosas y al mes siguiente se asignó la construcción de la planta a una empresa con la cual el IB tenía experiencia previa, con un sistema de contratos que había manejado antes, y comienzan las faenas (CIB, Acta $\mathrm{N}^{\circ} 164$, febrero de 1953). El Consejo reconoce por unanimidad a Salvador Boné por sus esfuerzos en el desarrollo de este proyecto y le otorga una bonificación (CIB, Acta $\mathrm{N}^{\circ} 166$, marzo de 1953)

La posición del IB cambia a fines de 1952 debido al nuevo régimen creado por la Ley 10.383. El Ministro de Salud, Dr. Sótero del Río, anuncia que: “en vista de haber entrado en vigencia el Reglamento del Consejo Nacional de Salud, deberán quedar suspendidas definitivamente las sesiones del Consejo del Instituto Bacteriológico de Chile, cuyas funciones se dan por terminadas" (CIB, Acta $\mathrm{N}^{\circ}$ 166, marzo de 1953: 460). El Instituto conforma un nuevo Consejo Técnico en el que no participa el Ministro y que sesiona por primera vez en agosto de 1953. A partir de entonces se hizo difícil la obtención de los presupuestos prometidos para la planta de penicilina en los plazos estipulados. En la primera reunión el Director de Salud se queja de la situación presupuestaria del Instituto y anuncia que los fondos para la planta deberían ser gestionados con el gobierno porque el Servicio de Salud no contaba con recursos para este objetivo. Naturalmente esto provoca una discusión donde el Director del IB argumenta que hay un compromiso del gobierno de Chile con la Unicef (Consejo Técnico Sesión $N^{\circ}$ 1, agosto de 1953). Los representantes del Servicio de Salud no asisten a las dos reuniones siguientes. El Dr. Etcheverry informa al Consejo de un memorándum del Ministro de Salud sobre los fondos requeridos "El Sr. Ministro le ha dicho que la inversión se disminuyó, lo que sería muy grave ya que habría que paralizar la construcción de la planta de penicilina, lo que equivaldría a desahuciar el convenio con la UNICEF" (Consejo Técnico N³3, 8 de Septiembre de 1953).

\section{Instalación y puesta en marcha de la nueva planta productiva}

Sabemos que a pesar de los problemas financieros la planta finalmente se terminó de construir y que la producción se masificó a partir de 1956. No tenemos detalles del proceso puesto que el volumen del libro de actas del Consejo Técnico que va de octubre de 1953 a octubre de 1960 está perdido o nunca existió. Los encargados de la biblioteca del ISP piensan que puede haber sido una de las bajas del pasado terremoto de 2010 .

Encontramos registros de la puesta en marcha de la planta en reportes de las Naciones Unidas según los cuales la fábrica se construyó dentro del plazo previsto y comenzó a operar a gran escala en 1956, logrando una producción de 320.000 unidades de penicilina potásica mensuales ese año ${ }^{33}$. El edificio y la mayor parte de las instalaciones, así como los ensayos de producción, se terminaron a fines de 1955, se disponía de materia prima para iniciar la producción y de personal contratado para el funcionamiento permanente de la planta ${ }^{34}$. La inspección de la asistencia técnica de las Naciones Unidas encontró que la producción era mayor que la prevista y se hicieron algunas recomendaciones para mejorar los procesos invirtiendo en nuevos equipos. Las Naciones Unidas aportaron recursos suplementarios para la planta en 1954 y 1957 , 
los que fueron complementados con montos equivalentes puestos por el gobierno chileno ${ }^{35}$.

El Boletín del Servicio Nacional de Salud (1957) informó que la producción de 1957 fue superior a los requerimientos de penicilina nacionales (1.700 kilos anuales para una demanda de 1.500), lo que permitió guardar una reserva para emergencias. Los periódicos locales informaron de las alabanzas al funcionamiento de la planta por parte del Dr. Chain y otros expertos de las Naciones Unidas en visita técnica (El Mercurio, 1957).

\section{Conclusiones}

En el curso de nuestra investigación identificamos las primeras menciones a la producción de penicilina en Chile y recurrimos a documentos y archivos históricos que no habían sido utilizados en investigaciones anteriores sobre el tema. Sobre esta base elaboramos una historia que involucra investigación, aprendizaje y desarrollo de las técnicas que llevaron a la gestación de la producción de penicilina en Chile. Creemos que este relato presenta una perspectiva desconocida que sitúa a Chile entre los pioneros en la exitosa industrialización del antibiótico.

Nuestra primera conclusión es que la planta inicial fue efectivamente una producción industrial en sentido estricto -y no piloto como se le ha llamado en ocasiones. Una producción industrial es aquella que llega a comercializarse, a tener una participación de mercado habiendo resuelto los problemas tecnológicos que implica producir para el consumo regular ${ }^{36,37}$. La producción chilena de penicilina tuvo una participación de mercado sostenida entre 1944 y 1954, resolvió problemas tecnológicos de aumento de producción, mejora de procesos, control de costos y cumplimiento de estándares de calidad. La gestión de la planta incluyó la gestión tecnológica tanto a nivel estratégico como a nivel operativo. A nivel estratégico el nivel directivo tomó decisiones considerando el calce del proyecto con la política organizacional, realizó procesos de vigilancia tecnológica internacional y analizó posibles alianzas. A nivel operativo, se organizaron procesos de adquisición de recursos tecnológicos (equipos y capacitaciones), adaptación de procesos (por ejemplo, incorporación de la cristalización), experimentación y resolución de problemas técnicos (por ejemplo, desarrollo de proveedores). El IB aprovechó su experiencia en el proceso productivo, en el manejo de contratos y relación con proveedores en la etapa de ampliación, es decir, completó el ciclo de gestión tecnológica.

La segunda conclusión es que el relato provisto se explica en las dimensiones de gobernanza y cambio tecnológico. Las decisiones tomadas por el IB fueron coherentes con la visión de lo que le correspondía hacer en cada etapa, considerando el peso de los distintos actores en la toma de decisiones. Así por ejemplo, aunque el Director del IB considerara desde un inicio conveniente generar alianzas con laboratorios tecnológicamente fuertes, primó la decisión del gobierno, representada en el Ministro de Salud, de privilegiar la independencia productiva por considerarla estratégica. A medida que la industria profundizaba en cuanto a despliegue de la nueva tecnología y se consolidaban actores en el mercado, resultaba más difícil competir y mantener el paso en cuanto actualización de procesos y desarrollo de nuevos productos. Esta etapa, que exige una estrategia de fortalecimiento o salida, se dio en un período de confusión respecto del rol del Instituto y de pérdida relativa de independencia e influencia en la toma de decisiones a nivel del gobierno -con la restructuración de principios de los $50 \mathrm{~s}$.

La última conclusión es que la nueva planta nació en condiciones poco prometedoras considerando el contexto internacional. Se construyó una planta de tamaño medio, que apenas satisfacía el consumo local, sin pretensión de exportar. Esta planta estaría unida a la red de Naciones Unidas que compartirían la componente de investigación y desarrollo. Este diseño de "externalizar el desarrollo" sumado a la estrechez de recursos y mayor dependencia en el manejo presupuestario del Instituto, implicó una gestión tecnológica de carácter pasivo ${ }^{38}$, es decir, concentrada en la operación

Agradecimientos. Las autoras agradecen la colaboración del bibliotecólogo de la Biblioteca Central del ISP, Sr. César Conejeros, y a todos quienes compartieron con nosotros sus vivencias y conocimiento sobre la planta de penicilina y nos concedieron entrevistas, contestaron nuestros correos o nos hicieron llegar documentos, agradecemos a: Q.F. Salvador Ballart, Dr. Yuri Carvajal, Dr (C) Q.F. José Luis García, Sr. Jorge Hernández, Dr. Walter Ledermann, Sr. Juan Montenegro, Q.F. Cecilia Morgado, Dr. Jorge Pacheco, Dr. Rodrigo Prado, Q.F. Eduardo Ramírez, Sra. Cristina Salazar y Q.I. Johnny Teperman. Quisiéramos agradecer también a auxiliares, técnicos y profesionales del ISP que nos aportaron algún dato o un contacto para una entrevista, animándonos a seguir nuestra investigación.

\section{Resumen}

La producción pionera de penicilina chilena es un desarrollo productivo que, si bien ha sido documentado, deja aún espacio para la investigación y discusión. Entre 1944 y 1973 el Instituto Bacteriológico de Chile produjo penicilina, siendo la etapa más conocida la posterior a 1953 cuando existió un convenio con las Naciones Unidas. Nuestra investigación se centró en construir un relato sobre la producción entre 1944 y 1954 a partir de archivos de la época y del contexto histórico nacional e internacional. Nuestros resultados sitúan a Chile entre los pioneros en la exitosa industrialización del antibiótico. Como conclusiones planteamos que la producción de la época estudiada fue una producción industrial y no una 
producción piloto - como se le ha llamado en algunos documentos y en los recuerdos de los funcionarios del ISP -; podemos explicar la trayectoria de la planta relacionando las dimensiones de cambio tecnológico y gobernanza; y, por último, creemos que la posterior ampliación de la planta, en el marco del convenio con las Naciones Unidas, se dio en un contexto de gobernanza poco favorable que auguraba una gestión de la innovación y la tecnológica de carácter pasivo.

\section{Referencias bibliográficas}

1.- Instituto de Salud Pública. ISP: Conocimiento, liderazgo e innovación en salud pública. Santiago de Chile: Instituto de Salud Pública; 2014.

2.- Instituto de Salud Pública. Historia del Instituto de Salud Pública de Chile 1892-2009. Camino al bicentenario. Santiago de Chile: Instituto de Salud Pública; 2009.

3.- Ledermann W. La historia de la penicilina y de su fabricación en Chile. Rev Chilena Infectol 2006; 23 (2): 172-6.

4.- García J. Instituto Bacteriológico de Chile, 97 años al servicio de la salud. Santiago de Chile: Ministerio de Salud; 1989.

5.- von Tunzelmann, G. N. Historical co-evolution of governance and technology in the industrial revolutions. StructuralChange and Economic Dynamics 2003; 14: 365-84.

6.- Camus P, Zúñiga F. La salud pública en la historia de Chile. Anales Chilenos de Historia de la Medicina 2007; 17 (2): 155-75.

7.- Bud R. Penicillin. Triumph and tragedy.Oxford: Oxford University Press; 2007.

8.- Bud, ibid.

9.- Burns M, Van Dijck P. The development of penicillin production in delft, the Netherlands, during World War II under nazi occupation. In A. I. Laskin, J. W. Bennett \& G. M. Gadd (Eds.), Advances in applied microbiology: Elsevier Science, USA; 2002, p. 51-185.

10.- Neushul P. Science, government and the mass production of penicillin. Journal of the History of Medicine and Allied Sciences 1993; 48 (4): 371-95.

11.- Richards A. Production of penicillin in the United States (1941-1946). Nature 1964; 201 (1): 441-6.

12.- Neushul, op. cit.

13.- Kraljevic, R. Recuerdos de un viejo infectólogo. Contribución a la historia de la infectología en Chile (1937-1970). Santiago de Chile; 1998.

14.- Brodsky M, Moya Bravo H. Penicilina. Rev Med Chile 1944; 22 (5): 405-12.

15.- Alessandri H, Gazmuri R. Uso clínico de la penicilina. Rev Med Chile 1944; 22 (9): 813-24.
16.- Acuña Zamora M, González Rodríguez O. Trombosis del seno cavernoso tratada con penicilina. Rev Med Chile 1944; 22 (10): 901-2.

17.- Yazigi R. Septicemia estafilococica tratada con penicilina. Rev Med Chile 1944; 22 (10): 902-5.

18.- Prado Tagle E, Gazmuri O, Laza de los Reyes M. Empiema pleural doble tratado con penicilina. Rev Med Chile 1944; 22 (11): 1003-5.

19.- Fritis E, Gazmuri R, Denegri A. Empiema pleural neumococico tratado con penicilina. Rev Med Chile 1944; 22 (11): 1005-7.

20.- Acuña G. Evolución de la terapia antimicrobiana: Lo que era, lo que es y lo que será. Rev Chilena Infectol 2003; 20 (1): 7-10.

21.- Kraljevic, op.cit.

22.- Allende S. La realidad médico social chilena. Santiago de Chile: Ministerio de Salubridad, Previsión y Asistencia Social; 1939.

23.- Bud, op. cit.

24.- Bud, ibid.

25.- Cardoso H T F, Mireille I. Carneiro, Pirro, Clotilde and Bona, Eline M.Produção de penicilina terapêutica. Memórias do Instituto Oswaldo Cruz 1945; 43 (1): 161-70.

26.- Bud, op. cit.

27.- Bud, ibid.

28.- Bud, ibid.

29.- Bud, ibid.

30.- Bud, ibid.

31- Naciones Unidas. United Nations International Children's emergency fund.Report to the executive board (22-24 April, 1952). New York: United Nations; 1952.

32.- Naciones Unidas, ibid.

33.- Naciones Unidas. Créditos recomendados por el director ejecutivo. Chile, equipo para una fábrica de penicilina: Naciones Unidas, Consejo Económico y Social; 1957.

34.- Naciones Unidas. Informe del director ejecutivo sobre la marcha de los trabajos: Desarrollo de los programas en América: Naciones Unidas Consejo Económico y Social; 1956.

35.- Naciones Unidas, 1957, op. cit.

36.- OECD. Frascati manual 2002: Proposed standard practice for surveys on research and experimental development, the measurement of scientific and technological activities: OECD Publishing; 2002.

37.- OECD. Oslo manual: Guidelines for collecting and interpreting innovation data (Third ed.): OECD; 2005.

38.- Viotti E B. National learning systems: A new approach on technical change in late industrializing economies and evidences from the cases of Brazil and South Korea. Science, Technology and Innovation Discussion Paper No. 12, Center for International Development, Harvard University; 2001. 